\title{
Autonomic Neuroscience: articles of interest appearing in other Frontiers journals
}

\author{
Vaughan G. Macefield ${ }^{1 *}$ and Joel C. Bornstein ${ }^{2}$ \\ ${ }^{1}$ School of Medicine, University of Western Sydney, Sydney, NSW, Australia \\ 2 Department of Physiology, The University of Melbourne, Melbourne, VIC, Australia \\ ${ }^{*}$ Correspondence: v.macefield@uws.edu.au \\ Edited by: \\ Paul P. Bertrand, University of New South Wales, Australia
}

Dear Readers of Frontiers in Autonomic Neuroscience,

As you are all aware, autonomic neuroscience is a multidisciplinary field, in which authors choose a journal based on its perceived impact but, more importantly, on its relevance and readership. Together, the Frontiers journals are broad in scope, yet the areas covered by individual journals within the Frontiers stable are necessarily narrower. Now, to facilitate your use of the Frontiers articles we are going to highlight those articles published in our sister journals that are relevant to us working in autonomic neuroscience.

So, here is a wrap-up of articles you may have missed over the last few months.

\section{FRONTIERS IN INTEGRATIVE PHYSIOLOGY}

Published on 1 Oct 2012

Autonomic markers of emotional processing: skin sympathetic nerve activity in humans during exposure to emotionally charged images

Rachael Brown, Cheree James, Luke A. Henderson and Vaughan G. Macefield

Published on 07 Aug 2012

Arterial baroreflex control of muscle sympathetic nerve activity under orthostatic stress in humans

Masashi Ichinose and Takeshi Nishiyasu

Published on 24 Jul 2012

Sympathetic regulation of vascular function in health and disease

Rosa M. Bruno, Lorenzo Ghiadoni, Gino Seravalle, Raffaella Dell'Oro, Stefano Taddei and Guido Grassi

Published on 18 Jul 2012

Microneurographic research in women

Qi Fu

Published on 17 Jul 2012

Upper gastrointestinal dysmotility after spinal cord injury: is diminished vagal sensory processing one culprit?

Gregory M. Holmes

Published on 09 Jul 2012

Plasticity of TRPV1-expressing sensory neurons mediating autonomic dysreflexia following spinal cord injury
Leanne M. Ramer, A. Peter van Stolk, Jessica A. Inskip, Matt S. Ramer and Andrei V. Krassioukov

Published on 26 Jun 2012

Autonomic dysfunction in heart failure and renal disease Jacqueline K. Phillips

Published on 25 Jun 2012

Somatosympathetic vasoconstrictor reflexes in human spinal cord injury: responses to innocuous and noxious sensory stimulation below lesion

Vaughan G. Macefield, Alexander R. Burton and Rachael Brown

Published on 07 Jun 2012

Association of cardiac baroreflex sensitivity with blood pressure transients: influence of sex and menopausal status

Jill N. Barnes, Luke J. Matzek, Nisha Charkoudian, Michael J. Joyner, Timothy B. Curry and Emma C. Hart

Published on 23 May 2012

Firing patterns of muscle vasoconstrictor neurones in respiratory disease

Vaughan G. Macefield

Published on 03 May 2012

Advantage of recording single-unit muscle sympathetic nerve activity in heart failure

Hisayoshi Murai, Masayuki Takamura and Shuichi Kaneko

Published on 26 Apr 2012

Sympathetic responses to central hypovolemia: new insights from microneurographic recordings

Kathy L. Ryan, Caroline A. Rickards, Carmen Hinojosa-Laborde, William H. Cooke and Victor A. Convertino

Published on 10 Apr 2012

Autonomic regulation during quiet and active sleep states in very preterm neonates

Sina Reulecke, Steffen Schulz and Andreas Voss

Published on 20 Feb 2012

Evidence and consequences of the central role of the kidneys in the pathophysiology of sympathetic hyperactivity

Eva E. Vink and Peter J. Blankestijn 


\section{Published on $07 \mathrm{Feb} 2012$}

Advances in sympathetic nerve recording in humans

Elisabeth Lambert, Dagmara Hering, Markus Schlaich and Gavin Lambert

Published on $02 \mathrm{Feb} 2012$

Effects of renal denervation on sympathetic activation, blood pressure, and glucose metabolism in patients with resistant hypertension

Markus P. Schlaich, Dagmara Hering, Paul Sobotka, Henry Krum, Gavin W. Lambert, Elisabeth Lambert and Murray D. Esler

Published on 12 Jan 2012

Prognostic indicators of cardiovascular risk in renal disease Cara M. Hildreth

Published on 03 Jan 2012

Brain renin-angiotensin system in hypertension, cardiac hypertrophy, and heart failure

Luciana A. Campos, Michael Bader and Ovidiu C. Baltatu

\section{FRONTIERS IN CARDIAC ELECTROPHYSIOLOGY}

Published on 24 Sep 2012

Cyclical modulation of human ventricular repolarization by respiration

\section{REFERENCES}

Barnes, J. N., Matzek, L. J., Charkoudian, N., Joyner, M. J., Curry, T. B., and Hart, E. C. (2012). Association of cardiac baroreflex sensitivity with blood pressure transients: influence of sex and menopausal status. Front. Physio. 3:187. doi: 10.3389/fphys.2012.00187

Brown, R., James, C., Henderson, L. A., and Macefield, V. G. (2012). Autonomic markers of emotional processing: skin sympathetic nerve activity in humans during exposure to emotionally charged images. Front. Physio. 3:394. doi: 10.3389/fphys.2012.00394

Bruno, R. M., Ghiadoni, L., Seravalle, G., Dell'Oro, R., Taddei, S., and Grassi, G. (2012). Sympathetic regulation of vascular function in health and disease. Front. Physio. 3:284. doi: 10.3389/fphys.2012.00284

Campos, L. A., Bader, M., and Baltatu, O. C. (2012). Brain reninangiotensin system in hypertension, cardiac hypertrophy, and heart failure. Front. Physio. 2:115. doi: 10.3389/fphys.2011.00115

Duncker, D. J., and Heinonen, I. H. (2012). Sympathetic limitation of exercise hyperemia: even hypoperfused muscle is not exempted. Front. Physio. 3:411. doi: 10.3389/fphys.2012 00411

Frasch, M. G., Frank, B., Last, M., and Müller, T. (2012). Time scales of autonomic information flow in near-term fetal sheep. Front. Physio. 3:378. doi: 10.3389/fphys.2012.00378

$\mathrm{Fu}$, Q. (2012). Microneurographic research in women. Front. Physio. 3:278. doi: 10.3389/fphys.2012.00278

Hägglund, H., Uusitalo, A., Peltonen, J. E., Koponen, A. S., Aho, J., Tiinanen, S., et al. (2012). Cardiovascular autonomic nervous system function and aerobic capacity in type 1 diabetes. Front. Physio. 3:356. doi: 10.3389/fphys.2012.00356

Hanson, B., Gill, J., Western, D., Gilbey, M. P., Bostock, J., Boyett, M. R., et al. (2012). Cyclical modulation of human ventricular repolarization by respiration. Front. Physio. 3:379. doi: 10.3389/fphys.2012.00379

Hildreth, C. M. (2012). Prognostic indicators of cardiovascular risk in renal disease. Front. Physio. 2:121. doi: 10.3389/fphys.2011.00121

Holmes, G. M. (2012). Upper gastrointestinal dysmotility after

Ben Hanson, Jaswinder Gill, David Western, Michael P. Gilbey, Julian Bostock, Mark R. Boyett, Henggui Zhang, Ruben Coronel and Peter Taggart

\section{FRONTIERS IN COMPUTATIONAL PHYSIOLOGY AND MEDICINE}

Published on 21 Sep 2012

Time scales of autonomic information flow in near-term fetal sheep

M. G. Frasch, B. Frank, M. Last and T. Müller

\section{FRONTIERS IN EXERCISE PHYSIOLOGY}

Published on 23 Oct 2012

Sympathetic limitation of exercise hyperemia: even hypoperfused muscle is not exempted

D. J. Duncker and I. H. Heinonen

\section{FRONTIERS IN CLINICAL AND TRANSLATIONAL PHYSIOLOGY}

Published on 7 Sep 2012

Cardiovascular autonomic nervous system function and aerobic capacity in type 1 diabetes

Harriet Hägglund, Arja Uusitalo, Juha E. Peltonen, Anne S. Koponen, Jyrki Aho, Suvi Tiinanen, Tapio Seppänen, Mikko Tulppo and Heikki O. Tikkanen

spinal cord injury: is diminished vagal sensory processing one culprit? Front. Physio. 3:277. doi: 10.3389/fphys.2012.00277

Ichinose, M., and Nishiyasu, T. (2012). Arterial baroreflex control of muscle sympathetic nerve activity under orthostatic stress in humans. Front. Physio. 3:314. doi: 10.3389/fphys.2012. 00314

Lambert, E., Hering, D., Schlaich, M., and Lambert, G. (2012) Advances in sympathetic nerve recording in humans. Front. Physio. 3:11. doi: 10.3389/fphys.2012. 00011

Macefield, V. G. (2012). Firing patterns of muscle vasoconstrictor neurons in respiratory disease. Front. Physio. 3:153. doi: 10.3389/fphys.2012.00153

Macefield, V. G., Burton, A. R., and Brown, R. (2012) Somatosympathetic vasoconstrictor reflexes in human spinal cord injury: responses to innocuous and noxious sensory stimulation below lesion. Front. Physio. 3:215. doi: 10.3389/fphys. 2012.00215

Murai, H., Takamura, M., and Kaneko, S. (2012). Advantage of recording single-unit muscle sympathetic nerve activity in heart failure. Front. Physio. 3:109. doi: 10.3389/fphys.2012.00109

Phillips, J. K. (2012). Autonomic dysfunction in heart failure and renal disease. Front. Physio. 3:219. doi: 10.3389/fphys.2012.00219

Ramer, L. M., van Stolk, A. P., Inskip, J. A., Ramer, M. S., and Krassioukov, A. V. (2012). Plasticity of TRPV1expressing sensory neurons mediating autonomic dysreflexia following spinal cord injury. Front. Physio. 3:257. doi: 10.3389/fphys. 2012.00257

Reulecke, S., Schulz, S., and Voss, A. (2012). Autonomic regulation during quiet and active sleep states in very preterm neonates. Front. Physio. 3:61. doi: 10.3389/fphys.2012.00061

Ryan, K. L., Rickards, C. A., HinojosaLaborde, C., Cooke, W. H., and Convertino, V. A. (2012). Sympathetic responses to central hypovolemia: new insights from microneurographic recordings. Front. Physio. 3:110. doi: 10.3389/fphys.2012.00110

Schlaich, M. P., Hering, D., Sobotka, P., Krum, H., Lambert, G. W., Lambert, E., et al. (2012). Effects of renal denervation on sympathetic activation, blood pressure, 
and glucose metabolism in patients with resistant hypertension. Front. Physio. 3:10. doi: 10.3389/fphys. 2012.00010

Vink, E. E., and Blankestijn, P. J. (2012). Evidence and consequences of the central role of the kidneys in the pathophysiology of sympathetic hyperactivity. Front. Physio. 3:29. of interest appearing in other Frontiers doi: 10.3389/fphys.2012.00029

Received: 21 November 2012; accepted: 04 December 2012; published online: 21 December 2012.

Citation: Macefield VG and Bornstein JC (2012) Autonomic Neuroscience: articles journals. Front. Neurosci. 6:184. doi: 10.3389/fnins.2012.00184

This article was submitted to Frontiers in Autonomic Neuroscience, a specialty of Frontiers in Neuroscience.

Copyright (c) 2012 Macefield and Bornstein. This is an open-access article distributed under the terms of the Creative Commons Attribution License, which permits use, distribution and reproduction in other forums, provided the original authors and source are credited and subject to any copyright notices concerning any third-party graphics etc. 